\title{
Influence of obesity on surgical complications of patients with ovarian tumors
}

\author{
HUIMIN LV and SUHUI WU \\ Department of Gynaecology and Obstetrics, Shanxi Dayi Hospital Affiliated to \\ Shanxi Medical University, Taiyuan, Shanxi 030000, P.R. China
}

Received June 11, 2018; Accepted February 7, 2019

DOI: $10.3892 / \mathrm{ol} .2019 .10103$

\begin{abstract}
Influence of obesity on surgical complications and survival of patients with ovarian tumors were investigated. In total, 362 patients who were diagnosed with ovarian cancer by biopsy in the Department of Pathology of Shanxi Dayi Hospital Affiliated to Shanxi Medical University from April 2012 to July 2017 were selected as research subjects for retrospective analysis. The patients were divided into the obesity group [body mass index $(B M I) \geq 28$ ] ( $n=64)$, the overweight group $(\geq 24 \mathrm{BMI}<28)(\mathrm{n}=124)$, the normal body weight group $(\geq 18.5 \mathrm{BMI}<24)(\mathrm{n}=108)$ and the low body weight group $(\mathrm{BMI}<18.5)(\mathrm{n}=66)$. The surgical conditions and postoperative complications of patients in the 4 groups were compared, and the patients were followed up for prognosis for one year, and their mortality rates were recorded. The surgical time, intraoperative blood loss amount and blood transfusion amount of the patients in the obesity group were the highest, followed by the overweight group $(\mathrm{P}<0.05)$. Among the 4 groups, the prognosis of patients in the obesity group was also the worst. The incidence rates of complications among all groups were compared, and the incidence rate of complications in the obesity group was the highest $(50.00 \%)$, followed by the overweight group (30.65\%), the low body weight group (13.64\%) and the normal body weight group $(4.63 \%),(\mathrm{P}<0.05)$. The prognosis follow-up results showed that the 1-year mortality rate in the obesity group was the highest (35.94\%), followed by the overweight group (28.23\%). For patients with ovarian cancer, obesity raises the risks of postoperative complications and worsens their prognosis. Therefore, indexes of patients with tumors associated with high BMI should be monitored more strictly after surgeries.
\end{abstract}

Correspondence to: Dr SuHui Wu, Department of Gynaecology and Obstetrics, Shanxi Dayi Hospital Affiliated to Shanxi Medical University, 99 Longcheng Avenue, Taiyuan, Shanxi 030000, P.R. China

E-mail: wey252@163.com; shwu1215@163.com

Key words: ovarian tumors, obesity, BMI, complications

\section{Introduction}

As one of the most common malignant tumors in women, ovarian cancer ranks the third in incidence rate among all gynecologic tumors (1). The statistical results by Oza et al (2) showed that 1.6 million patients were newly diagnosed with ovarian cancer in 2015 globally. At present, not only the incidence rate of ovarian cancer is on the increase annually, but also an increasing number of young people are susceptible to the disease (3). The study conducted by Kuchenbaecker et al (4) indicated that ovarian cancer will be the first among all gynecologic tumors in incidence rate by 2050 .

As ovarian cancer has no significant signs in early stage, most patients have developed mid-late stage ovarian cancer at diagnosis, not only increasing the difficulty of treatment, but also worsening the prognosis of patients (5). Postoperative five-year mortality rate of patients with ovarian cancer is up to $72.8 \%$, which is the highest among those of gynecologic diseases, according to the statistics by Bachmayr-Heyda et al (6). With the development of modern medical technology, relatively stable research results in the treatment of ovarian cancer have been achieved, and the survival rate after surgery of patients has been on the increase year by year (7). However, the study conducted by Lauby-Secretan et al (8) proved that body weight is a key factor influencing the postoperative prognosis of patients with tumors, but there has been no report in literature on ovarian cancer so far. Therefore, by studying the postoperative conditions of ovarian cancer patients with different body weights, this study provides reference and guidance for future clinical treatment of ovarian cancer.

\section{Patients and methods}

General data. A total of 362 patients who were diagnosed with ovarian cancer by biopsy in the Department of Pathology of Shanxi Dayi Hospital Affiliated to Shanxi Medical University (Taiyuan, China) from April 2012 to July 2017 were selected as research subjects and analyzed retrospectively. The patients were aged between 35 and 55 years, with an average age of $44.78 \pm 9.17$ years. Inclusion criteria were: i) patients diagnosed with ovarian cancer through biopsy in the Department of Pathology of Shanxi Dayi Hospital, ii) patients aged 35-55 years, iii) patients who underwent surgeries in the hospital after diagnosis of the disease, iv) patients whose medical records were 
Table I. Comparison of clinical data of the 4 groups of patients.

\begin{tabular}{lcccccc}
\hline Variables & $\begin{array}{c}\text { Obesity } \\
\text { group (n=64) }\end{array}$ & $\begin{array}{c}\text { Overweight } \\
\text { group }(\mathrm{n}=124)\end{array}$ & $\begin{array}{c}\text { Normal body weight } \\
\text { group (n=108) }\end{array}$ & $\begin{array}{c}\text { Low body weight } \\
\text { group (n=66) }\end{array}$ & f value & P-value \\
\hline Age (years) & $45.27 \pm 8.16$ & $44.68 \pm 9.07$ & $43.54 \pm 8.57$ & $44.17 \pm 7.04$ & 0.66 & 0.58 \\
Course of illness (days) & $17.84 \pm 5.76$ & $18.34 \pm 4.07$ & $19.27 \pm 5.88$ & $18.07 \pm 6.04$ & 1.25 & 0.29 \\
$\begin{array}{l}\text { Pathological staging } \\
\quad\end{array}$ & & & & 0.58 & 0.61 \\
$\quad$ Stage I-II & $21(32.81)$ & $37(29.84)$ & $33(30.56)$ & $23(34.85)$ & & \\
$\quad$ Stage III-IV & $43(67.19)$ & $87(70.16)$ & $75(69.44)$ & $43(65.15)$ & & 0.41 \\
Metastasis of lymph nodes & & & & & & 0.69 \\
$\quad$ Yes & $18(28.13)$ & $34(27.42)$ & $29(26.85)$ & $18(26.85)$ & & \\
No & $46(71.88)$ & $90(72.58)$ & $79(73.15)$ & $48(73.15)$ & & \\
\hline
\end{tabular}

complete and v) patients who co-operated with the instructions of our medical staff. Exclusion criteria were: i) patients complicated with other cardiovascular and cerebrovascular diseases, ii) patients associated with other tumors, iii) patients with surgical tolerance, iv) patients who were sensitive to drugs, v) pregnant patients, vi) patients who had been bedridden for a long time, vii) patients with physical disability and viii) patients who were transferred to other hospitals halfway.

Methods. All the patients underwent ovarian tumor resections in Shanxi Dayi Hospital Affiliated to Shanxi Medical University after definite diagnosis and also received nursing care and treatments in the Shanxi Dayi Hospital. According to body fat health standard (8), the patients were divided into the obesity group [body mass index $(\mathrm{BMI}) \geq 28$ ], the overweight group ( $\geq 24 \mathrm{BMI}<28$ ), the normal body weight group $(1 \geq 8.5 \mathrm{BMI}<24)$ and the low body weight group (BMI <18.5). Conditions of postoperative recovery and complications of patients in each group during hospitalization were recorded, and the prognosis of the patients was followed up for one year by means of telephone, e-mail or hospital re-examination. The follow-up period ended on May 30, 2018, and the events for termination of the follow-up period included the death of patients or loss to follow up, and the life conditions and survival of patients after discharge were recorded.

The study was approved by the Ethics Committee of Shanxi Dayi Hospital Affiliated to Shanxi Medical University. Signed informed consents were obtained from the patients the guardians.

Observation indexes. Clinical data, surgical time, intraoperative blood loss amount, intraoperative blood transfusion amount, time of postoperative passage of gas, length of stay, complications, prognosis and survival rate were factors analyzed.

Statistical analysis. Statistical Product and Service Solutions (SPSS) 22.0 software (IBM Corp., Armonk, NY, USA) was employed for the analysis and processing of the data, measurement data were expressed by rate, and the comparison between two groups were analyzed using the Chi-square test. Enumeration data were expressed by mean \pm standard deviation, and comparisons between two groups were evaluated using the paired t-test. Comparisons among multiple groups were conducted using analysis of variance and the LSD post hoc test. The Kaplan-Meier method was used to calculate the survival rate, and comparisons of survival rates were assessed by log-rank test. $\mathrm{P}<0.05$ was considered to indicate a statistically significant difference.

\section{Results}

Comparison of clinical data of patients. The patients were divided into the obesity group $(n=64)$, the overweight group $(n=124)$, the normal body weight group $(n=108)$ and the low body weight group $(n=66)$ based on their BMI. Age, course of illness, pathological staging and metastasis of lymph nodes were compared among the 4 groups of patients, and no significant differences were noted, indicating that the 4 groups were comparable (Table I).

Comparison of surgical conditions. Comparison in surgical time in the 4 groups of patients were performed, indicating that the surgical time of the normal body weight group was $145.37 \pm 27.68 \mathrm{~min}$, which was the shortest, and that of the the obesity group $(214.33 \pm 27.84 \mathrm{~min})$ was the longest $(\mathrm{P}<0.05)$, followed by that of the overweight group (184.37 $\pm 29.33 \mathrm{~min})$ $(\mathrm{P}<0.05)$. In terms of intraoperative blood loss amount, the obesity group had the highest blood loss, up to $342.17 \pm 42.37 \mathrm{ml}$, followed by the overweight group $(284.68 \pm 50.27 \mathrm{ml})(\mathrm{P}<0.05)$, and the normal group had the lowest blood loss $(197.64 \pm 33.84 \mathrm{ml})$ $(\mathrm{P}<0.05)$. Similarly, among patients in the 4 groups, the obesity group had the highest intraoperative blood transfusion, up to $427.68 \pm 50.72 \mathrm{ml}$, followed by the overweight group $(354.73 \pm 33.86)(\mathrm{P}<0.05)$, and the lowest blood transfusion was detected in the normal group $(197.64 \pm 33.84)(\mathrm{P}<0.05)$ (Table II).

Postoperative conditions. The lengths of stay of patients in the 4 groups were compared, and the results showed that the length of stay in the obesity group was $16.24 \pm 3.67$ days, which was the longest, followed by those in the overweight group (14.37 \pm 2.33 days), the low body weight group (12.86 \pm 2.07 days), and the normal group (9.63 \pm 2.15 days), which was the shortest $(\mathrm{P}<0.05)$. The time of postoperative passage of gas in the 4 groups was in the same order as above, i.e., the obesity group had the longest time of postoperative passage of gas $(42.68 \pm 12.33 \mathrm{~h})$, followed by the overweight 
Table II. Comparison in surgical conditions among the 4 groups of patients.

\begin{tabular}{|c|c|c|c|c|c|c|}
\hline Variables & $\begin{array}{c}\text { Obesity } \\
\text { group }(n=64)\end{array}$ & $\begin{array}{l}\text { Overweight } \\
\text { group }(\mathrm{n}=124)\end{array}$ & $\begin{array}{l}\text { Normal body weight } \\
\text { group }(n=108)\end{array}$ & $\begin{array}{l}\text { Low body weight } \\
\text { group }(\mathrm{n}=66)\end{array}$ & f value & P-value \\
\hline Surgical time (min) & $214.33 \pm 27.84$ & $184.37 \pm 29.33^{\mathrm{a}}$ & $145.37 \pm 27.68^{\mathrm{a}, \mathrm{b}}$ & $172.14 \pm 30.57^{\mathrm{a}-\mathrm{c}}$ & 79.17 & $<0.01$ \\
\hline $\begin{array}{l}\text { Intraoperative blood loss } \\
\text { amount (ml) }\end{array}$ & $342.17 \pm 42.37$ & $284.68 \pm 50.27^{\mathrm{a}}$ & $197.64 \pm 33.84^{\mathrm{a}, \mathrm{b}}$ & $263.17 \pm 45.07^{\mathrm{a}-\mathrm{c}}$ & 253.30 & $<0.01$ \\
\hline $\begin{array}{l}\text { Intraoperative blood } \\
\text { transfusion amount (ml) }\end{array}$ & $427.68 \pm 50.72$ & $354.73 \pm 33.86^{\mathrm{a}}$ & $247.36 \pm 45.23^{\mathrm{a}, \mathrm{b}}$ & $321.76 \pm 39.27^{\mathrm{a}-\mathrm{c}}$ & 274.03 & $<0.01$ \\
\hline
\end{tabular}

${ }^{\mathrm{a}} \mathrm{P}<0.05$, compared with the obesity group. ${ }^{\mathrm{b}} \mathrm{P}<0.05$, compared with the overweight group. ${ }^{\mathrm{c}} \mathrm{P}<0.05$, compared with the normal body weight group.

Table III. Comparison of complications among the 4 groups of patients.

\begin{tabular}{|c|c|c|c|c|c|c|}
\hline Compications experienced & $\begin{array}{c}\text { Obesity } \\
\text { group }(n=64)\end{array}$ & $\begin{array}{c}\text { Overweight } \\
\text { group }(\mathrm{n}=124)\end{array}$ & $\begin{array}{l}\text { Normal body weight } \\
\text { group }(\mathrm{n}=108)\end{array}$ & $\begin{array}{l}\text { Low body weight } \\
\text { group }(\mathrm{n}=66)\end{array}$ & f value & P-value \\
\hline Bleeding & $17(26.56)$ & $12(9.68)$ & $4(3.70)$ & $5(7.58)$ & & \\
\hline Infection of incision & $9(14.06)$ & $4(3.23)$ & $1(0.93)$ & $2(3.03)$ & & \\
\hline Urinary retention & $7(10.94)$ & $3(2.42)$ & $2(1.85)$ & $2(3.03)$ & & \\
\hline Intestinal obstruction & $12(18.75)$ & $8(6.45)$ & $0(0)$ & $3(4.55)$ & & \\
\hline Pulmonary infection & $7(10.94)$ & $3(2.42)$ & $0(0)$ & $0(0)$ & & \\
\hline Diarrhea & $11(17.19)$ & $6(4.84)$ & $1(0.93)$ & $3(4.55)$ & & \\
\hline Venous thrombosis & $3(4.69)$ & $1(0.81)$ & $0(0)$ & $0(0)$ & & \\
\hline Others & $8(12.50)$ & $8(6.45)$ & $2(1.85)$ & $3(4.55)$ & & \\
\hline Incidence rates of complications (\%) & 50.00 & $30.65^{\mathrm{a}}$ & $4.63^{\mathrm{a}, \mathrm{b}}$ & $13.64^{\mathrm{a}-\mathrm{c}}$ & 67.82 & $<0.01$ \\
\hline
\end{tabular}

${ }^{a} \mathrm{P}<0.05$, compared to the obesity group. ${ }^{\mathrm{b}} \mathrm{P}<0.05$, compared to the overweight group. ${ }^{\mathrm{c}} \mathrm{P}<0.05$, compared to the normal body weight group.

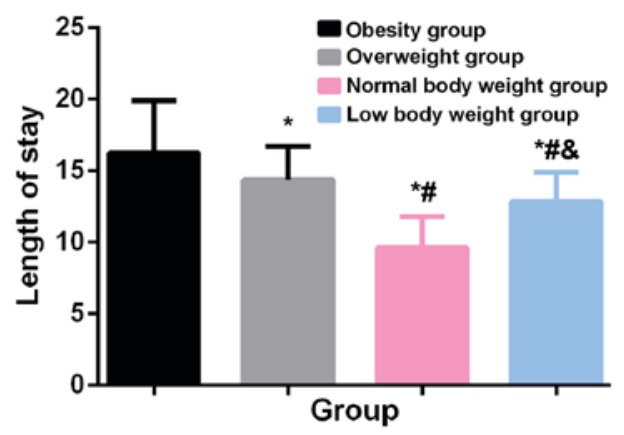

Figure 1. Comparison of the length of stay among the 4 groups of patients. ${ }^{*} \mathrm{P}<0.05$, compared to the obesity group. ${ }^{.} \mathrm{P}<0.05$, compared to the overweight group. ${ }^{\circledR} \mathrm{P}<0.05$, compared to the normal body weight group.

group, the low body weight group and the normal body weight group $(\mathrm{P}<0.05)$ (Figs. 1 and 2).

Complications. A total of 32 patients in the obesity group, 38 patients in the overweight group, 5 patients in the normal body weight group and 9 patients in the low body weight group had complications. Postoperative complications of the patients mainly included bleeding, infection of incision, urinary retention, intestinal obstruction, pulmonary infection, diarrhea, and venous thrombosis. All the complications were the most

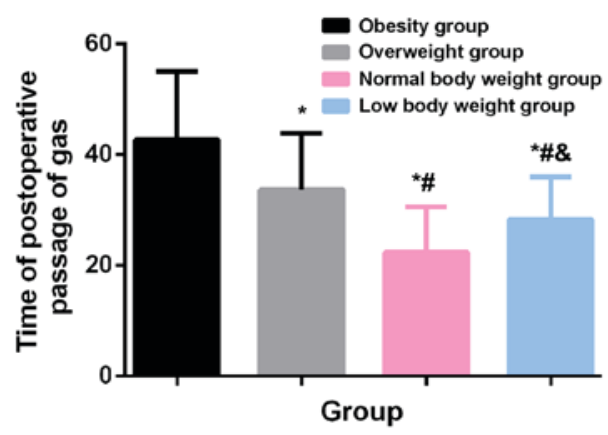

Figure 2. Comparison of the time of postoperative passage of gas among the 4 groups of patients. "P $\mathrm{P}<0.05$, compared to the obesity group. ${ }^{.} \mathrm{P}<0.05$, compared to the obesity group. ${ }^{\&} \mathrm{P}<0.05$, compared to the normal body weight group.

serious in the obesity group. The comparison results indicated that the incidence rates of complications in the obesity group, overweight group, low body weight group and the normal body weight group were 50.00, 30.65, 13.64 and $4.63 \%$, respectively $(\mathrm{P}<0.05)$ (Table III).

Prognosis and survival rate. Among the 362 patients, 354 patients were successfully followed up, with a success rate of follow-up of $97.79 \%$. There were 3 cases in the obesity group, 3 cases in the overweight group, 1 case in the normal body weight 
Table IV. Prognosis and survival rates of patients in the 4 groups.

\begin{tabular}{|c|c|c|c|c|c|c|}
\hline Time period & $\begin{array}{c}\text { Obesity } \\
\text { group }(\mathrm{n}=61)\end{array}$ & $\begin{array}{l}\text { Overweight } \\
\text { group }(\mathrm{n}=121)\end{array}$ & $\begin{array}{l}\text { Normal body weight } \\
\text { group }(\mathrm{n}=107)\end{array}$ & $\begin{array}{l}\text { Low body weight } \\
\text { group }(n=64)\end{array}$ & f value & P-value \\
\hline First month & 59 (96.72) & $117(96.69)$ & $105(98.13)$ & $62(96.88)$ & & \\
\hline Sixth month & $50(81.97)$ & $101(83.47)$ & 99 (92.52) & $56(87.50)$ & & \\
\hline Twelfth month & $41(67.21)$ & $89(73.55)$ & 95 (88.79) & $50(78.13)$ & & \\
\hline Total mortality rate (\%) & 35.94 & $28.23^{\mathrm{a}}$ & $12.04^{\mathrm{a}, \mathrm{b}}$ & $24.24^{\mathrm{a}-\mathrm{c}}$ & 56.21 & $<0.01$ \\
\hline
\end{tabular}

${ }^{\mathrm{a}} \mathrm{P}<0.05$, compared with the obesity group. ${ }^{\mathrm{b}} \mathrm{P}<0.05$, compared with the overweight group. ${ }^{\mathrm{c}} \mathrm{P}<0.05$, compared with the normal body weight group.

group and 2 cases in the low body weight group who were lost to follow-up. One-year mortality rate of the obesity group was $35.94 \%$, significantly higher than those of the other three groups $(\mathrm{P}<0.05)$. The 1-year mortality rate of the overweight group was $28.23 \%$, followed by those of the low body weight group $(24.24 \%)$ and the normal body weight group $(12.04 \%)(\mathrm{P}<0.05)$. The differences were statistically significant (Table IV).

\section{Discussion}

Due to high incidence rate and high mortality rate, ovarian cancer has become a vital issue in clinical gynecology, and it is urgent to make a breakthrough in this field (9). Currently, cytoreductive surgery is the most effective measure to treat tumors (10). However, because of the special body structure of females, ovarian lesions generally involve large areas and are difficult to identify, and cytoreductive surgery cannot thoroughly kill all cancer cells in patients, very easily resulting in the recurrence and deterioration of ovarian cancer (11). Therefore, ovarian resection remains the major procedure for clinical treatment of ovarian cancer (12). Although the surgical technique has become relatively mature, the prognosis of patients with ovarian cancer is not satisfactory. Numerous studies have evidenced that the prognosis of patients with ovarian cancer is closely associated with many factors, of which BMI is highly representative (13-15). As modern society develops rapidly, living conditions have been increasingly improved, and obesity has become one of the problems affecting most individuals. Due to high BMI, obese patients are very vulnerable to diabetes and cardiovascular disease (16). There have been very few studies worldwide on the influence of BMI on patients with ovarian cancer. Therefore, this study, by means of analyzing the survival and postoperative complications of patients with different BMIs who underwent ovarian cancer resection, aimed to evaluate the influence of BMI on ovarian cancer resection, so as to provide reliable reference for clinical treatment of such patients in the future.

The results of this experiment demonstrated that the obesity group ranked the first in terms of surgical time, intraoperative blood loss amount, blood transfusion amount, length of stay and complications $(\mathrm{P}<0.05)$, and its mortality rate was the highest $(\mathrm{P}<0.05)$, followed by the overweight group, the low body weight group and the normal body weight group. Ovarian cancer resection is a traumatic surgery involving large areas, and patients with extremely high BMI have more subcutaneous fat and thicker fat layer, which not only affect field of view and operation of the surgeon during surgeries, but also improve the difficulty of suturing due to large fat tension in the suture incision, thus resulting in the longest surgical time, and the largest amount of intraoperative blood loss and blood transfusion in the obesity group. In addition, because of excessively thick fat layer which affects the healing of the incision, patients are more susceptible to fat liquefaction and infection of incision (17). Moreover, obese patients tend to sweat more, making it is difficult to keep the incision dry, which results in the infection of incision. In addition, ovarian cancer resection can damage vesical plexus of patients very easily, thus lowering sensitivity of the bladder. Moreover, the bladder may be displaced as it loses support after removal of the ovary, and the accumulated urine cannot be discharged, thereby resulting in urinary retention (18). Due to accumulation of subcutaneous fats, internal organs of obese patients are surrounded by a large amount of adipose tissues, which will affect various functions of the patients to a certain extent and retard the recovery of tissues in the body, thus resulting in urinary retention, diarrhea and other complications in patients with ovarian cancer. In addition, the accumulation of subcutaneous fats can extremely easily lead to abdominal distention, backward extension of thoracic vertebrae, lumbar lordosis and other dislocations in patients, which compress the normal movements of the ribs and chest, making patients more vulnerable to shortness of breath and respiratory arrest after surgeries (19). Moreover, lungs cannot be stably supplied with nutrients, and are therefore more susceptible to infection. The accumulation of adipose tissues in obese patients also affects normal blood supply of the vessels, thus causing blood cell blockage and accelerating the formation of venous thrombosis and embolus. The study by Tremaroli et al (20) also proved that patients with high BMI have worse prognosis after gastrointestinal surgery, which confirms the results of this experiment.

In this experiment, postoperative complications of patients suffering from ovarian cancer with different BMI were compared, research subjects were selected in strict accordance with inclusion and exclusion criteria, and comparison and analysis were performed using statistical analysis methods. However, due to the limited conditions, the experiment still had deficiencies. For example, a small cardinal number of research subjects and short prognosis follow-up time may cause changes in the prognosis and survival of patients. We will follow up the prognosis of patients for a longer time and constantly improve and perfect the experiment to obtain the most accurate results.

In conclusion, for patients with ovarian cancer, obesity can raise the risks of postoperative complications and worsen 
their prognosis. In clinical practice, therefore, various indexes of tumor patients with high BMI should be monitored more strictly after surgeries.

\section{Acknowledgements}

Not applicable.

\section{Funding}

No funding was received.

\section{Availability of data and materials}

The datasets used and/or analyzed during the present study are available from the corresponding author on reasonable request.

\section{Authors' contributions}

HL drafted the manuscript. HL analyzed and interpreted clinical data, surgical time, intraoperative blood loss amount, intraoperative blood transfusion amount, time of postoperative passage of gas, length of stay. SW analyzed complications, prognosis and survival rate. Both authors read and approved the final study.

\section{Ethics approval and consent to participate}

The study was approved by the Ethics Committee of Shanxi Dayi Hospital Affiliated to Shanxi Medical University (Taiyuan, China). Signed informed consents were obtained from the patients the guardians.

\section{Patient consent for publication}

Not applicable.

\section{Competing interests}

The authors declare that they have no competing interests.

\section{References}

1. Jacobs IJ,Menon U,Ryan A, Gentry-Maharaj A,Burnell M,KalsiJK, Amso NN, Apostolidou S, Benjamin E, Cruickshank D, et al: Ovarian cancer screening and mortality in the UK Collaborative Trial of Ovarian Cancer Screening (UKCTOCS): A randomised controlled trial. Lancet 387: 945-956, 2016.

2. Oza AM, Cibula D, Benzaquen AO, Poole C, Mathijssen RH, Sonke GS, Colombo N, Śpaček J, Vuylsteke P, Hirte H, et al: Olaparib combined with chemotherapy for recurrent platinum-sensitive ovarian cancer: A randomised phase 2 trial. Lancet Oncol 16: 87-97, 2015.

3. Hamanishi J, Mandai M, Ikeda T, Minami M, Kawaguchi A, Murayama T, Kanai M, Mori Y, Matsumoto S, Chikuma S, et al: Safety and antitumor activity of anti-PD-1 antibody, nivolumab, in patients with platinum-resistant ovarian cancer. J Clin Oncol 33: 4015-4022, 2015.

4. Kuchenbaecker KB, Ramus SJ, Tyrer J, Lee A, Shen HC, Beesley J, Lawrenson K, McGuffog L, Healey S, Lee JM, et al; EMBRACE; GEMO Study Collaborators; Breast Cancer Family Registry; HEBON; KConFab Investigators; Australian Cancer Study (Ovarian Cancer Investigators); Australian Ovarian Cancer Study Group; Consortium of Investigators of Modifiers of BRCA1 and BRCA2: Identification of six new susceptibility loci for invasive epithelial ovarian cancer. Nat Genet 47: 164-171, 2015.
5. Falconer H, Yin L, Grönberg H and Altman D: Ovarian cancer risk after salpingectomy: A nationwide population-based study. J Natl Cancer Inst 107: 410, 2015.

6. Bachmayr-Heyda A, Reiner AT, Auer K, Sukhbaatar N, Aust S, Bachleitner-Hofmann T, Mesteri I, Grunt TW, Zeillinger R and Pils D: Correlation of circular RNA abundance with proliferation exemplified with colorectal and ovarian cancer, idiopathic lung fibrosis, and normal human tissues. Sci Rep 5: 8057, 2015.

7. Kim G, Ison G, McKee AE, Zhang H, Tang S, Gwise T, Sridhara R, Lee E, Tzou A, Philip R, et al: FDA approval summary: Olaparib monotherapy in patients with deleterious germline BRCA-mutated advanced ovarian cancer treated with three or more lines of chemotherapy. Clin Cancer Res 21: 4257-4261, 2015.

8. Lauby-Secretan B, Scoccianti C, Loomis D, Grosse Y, Bianchini F and Straif K; International Agency for Research on Cancer handbook working group: Body fatness and cancer - viewpoint of the IARC working group. N Engl J Med 375: 794-798, 2016.

9. Lu Y, Day FR, Gustafsson S, Buchkovich ML, Na J, Bataille V, Cousminer DL, Dastani Z, Drong AW, Esko T, et al: New loci for body fat percentage reveal link between adiposity and cardiometabolic disease risk. Nat Commun 7: 10495, 2016.

10. Rebbeck TR, Mitra N, Wan F, Sinilnikova OM, Healey S, McGuffog L, Mazoyer S, Chenevix-Trench G, Easton DF, Antoniou AC, et al; CIMBA Consortium: Association of type and location of BRCA1 and BRCA2 mutations with risk of breast and ovarian cancer. JAMA 313: 1347-1361, 2015.

11. Walker JL, Powell CB, Chen LM, Carter J, Bae Jump VL, Parker LP, Borowsky ME and Gibb RK: Society of Gynecologic Oncology recommendations for the prevention of ovarian cancer. Cancer 121: 2108-2120, 2015.

12. Wang F, Zhou J, Xie X, Hu J, Chen L, Hu Q, Guo H and Yu C: Involvement of SRPK1 in cisplatin resistance related to long non-coding RNA UCA1 in human ovarian cancer cells. Neoplasma 62: 432-438, 2015.

13. Hareyama H, Hada K, Goto K, Watanabe S, Hakoyama M, Oku K, Hayakashi Y, Hirayama E and Okuyama K: Prevalence, classification, and risk factors for postoperative lower extremity lymphedema in women with gynecologic malignancies: A retrospective study. Int J Gynecol Cancer 25: 751-757, 2015.

14. McDermott FD, Heeney A, Kelly ME, Steele RJ, Carlson GL and Winter DC: Systematic review of preoperative, intraoperative and postoperative risk factors for colorectal anastomotic leaks. Br J Surg 102: 462-479, 2015

15. Zhang WW, Liu KJ, Hu GL and Liang WJ: Preoperative platelet/lymphocyte ratio is a superior prognostic factor compared to other systemic inflammatory response markers in ovarian cancer patients. Tumour Biol 36: 8831-8837, 2015.

16. ShunginD,WinklerTW,Croteau-ChonkaDC,FerreiraT,LockeAE, Mägi R, Strawbridge RJ, Pers TH, Fischer K, Justice AE, et al; ADIPOGen Consortium; CARDIOGRAMplusC4D Consortium; CKDGen Consortium; GEFOS Consortium; GENIE Consortium; GLGC; ICBP; International Endogene Consortium; LifeLines Cohort Study; MAGIC Investigators; MuTHER Consortium; PAGE Consortium; ReproGen Consortium: New genetic loci link adipose and insulin biology to body fat distribution. Nature 518: 187-196, 2015.

17. Yu H, Di J, Bao Y, Zhang P, Zhang L, Tu Y, Han X and Jia W: Visceral fat area as a new predictor of short-term diabetes remission after Roux-en-Y gastric bypass surgery in Chinese patients with a body mass index less than $35 \mathrm{~kg} / \mathrm{m}^{2}$. Surg Obes Relat Dis 11: 6-11, 2015.

18. Osborn DJ, Kaufman MR, Mock S, Guan MJ, Dmochowski RR and Reynolds WS: Urinary retention rates after intravesical onabotulinumtoxinA injection for idiopathic overactive bladder in clinical practice and predictors of this outcome. Neurourol Urodyn 34: 675-678, 2015.

19. Schafer AL, Li X, Schwartz AV, Tufts LS, Wheeler AL, Grunfeld C, Stewart L, Rogers SJ, Carter JT, Posselt AM, et al: Changes in vertebral bone marrow fat and bone mass after gastric bypass surgery: A pilot study. Bone 74: 140-145, 2015.

20. Tremaroli V, Karlsson F, Werling M, Ståhlman M, KovatchevaDatchary P, Olbers T, Fändriks L, le Roux CW, Nielsen J and Bäckhed F: Roux-en-Y gastric bypass and vertical banded gastroplasty induce long-term changes on the human gut microbiome contributing to fat mass regulation. Cell Metab 22: 228-238, 2015.

This work is licensed under a Creative Commons Attribution-NonCommercial-NoDerivatives 4.0 International (CC BY-NC-ND 4.0) License. 